\title{
¿Sólo una virreina consorte de la Nueva España? 1660-1664. La II marquesa de Leiva y II condesa de Baños/
}

\author{
Only one vicereine consort of New Spain? 1660-1664. \\ The II marquise of Leiva and II countess of Baños
}

\author{
Isabel Arenas Frutos \\ Universidad de Huelva
}

Estudio centrado en doña Mariana Isabel de Leiva y Mendoza, quien, al ser hija única, heredó los títulos de marquesa de Leiva y condesa de Baños, siendo este último usado por su esposo Juan de la Cerda, virrey de Nueva España entre 1660 y 1684, al resultar más importante que el suyo propio. Nada más arribar a tierras mexicanas, esta familia despertó allí una franca antipatía y la señora virreina fue duramente criticada por su fuerte carácter y don de mando, al extralimitarse en las funciones propias que, en la época, se atribuían a una consorte del máximo gobernante novohispano. Tampoco sus dos hijos mayores, escaparon a las murmuraciones, por ser alocados y pendencieros. Fue, por tanto, una mujer fuerte, alejada de los cánones de invisibilidad femenina de su tiempo, aunque usara frecuentemente su influencia a través de sus problemas y enfermedades.

Palabras Clave: Nueva España; Ciudad de México; Virreyes; Grandes familias; Género.

This study focuses on doña Mariana Isabel de Leiva y Mendoza. Being a single daughter, she had the right of holding the titles of marquise of Leiva and countess of Baños. This last titl e was held by her husband don Juan de la Cerda, viceroy of New Spain between 1660 and 1664, as it was more important that the one he already held. Upon their arrival in mexicans lands, this family experienced a sincere rejection from all inhabitants and the vicereine was harshly criticised for her strong character and fondness for leadership, surpassing the duties which, at the time, were assigned to the partners of the highest governamental personality. Her two elder sons, did not escape either censorships, as they were wild and reckless youngsters. She was then, a strong woman, away from the model of female invisibility so common for her time, even if she would use her influence with arguments related to her problems and illnesses.

Keywords: New Spain; City of Mexico; Viceroys; Great Families; Gender Studies. 
En la historia colonial del Nuevo Mundo, el más alto poder residía en los virreyes y las actividades de éstos han sido objeto de documentos y posterior bibliografía, realizándose amplias investigaciones y estudios en torno a tan insignes personajes; pero, ¿y las virreinas? Señala S. Sefchovich que "son mujeres que no existen en la Historia" y que "a menos que el hombre fuera soltero o viudo, ellas venían como parte del equipaje de tan digno señor". ${ }^{1}$ Gozaban de ser las legítimas, pero en contraposición, las podríamos denominar como esas grandes (tanto por su estamento nobiliario, en la mayoría de las circunstancias, como por su número) desconocidas.

A las mujeres siempre se les ha adjudicado el papel de sujeto pasivo, subordinadas al esposo, destacándose como gran cualidad y obligatoriedad, sobre todo entre las familias de un alto estatus social, su "presencia y a la vez, transparencia", como se tituló un libro coordinado por C. Ramos. ${ }^{2}$ Pero, ¿qué ocurría si la señora era casi una igual a su cónyuge — títulos aristocráticos, buena situación económica, talante enérgico-, e incluso, en algunas facetas le superaba? Se llega a ejercitar, en ciertos casos, el denominado "poder transversal"; ella era, en realidad, la que llevaba las riendas aunque, si esta anómala situación trascendía, podía ser objeto de murmuraciones, denunciada y vituperada, incluso por miembros de la Iglesia y la sociedad en general, y en este caso de la Nueva España.

El texto que citamos a continuación, aplicado a la protagonista de nuestro estudio, es buen ejemplo de lo comentado:

“... se ha dicho que está la virreyna muy enferma y a ninguno he visto compadecido, antes si, a muchos deseosos de que Dios se la lleve...".

Duras son las palabras vertidas en este corto párrafo pues, aunque las pudiéramos tachar de evidente partidismo, desgraciadamente no fue así, y nos ratifican el concepto general, tan nefasto, que se tenía de esta noble y

1 Sefchovich, 1999, pp. 13 y 34. En la primera edición, la autora analizó el papel de las virreinas de la etapa colonial en las páginas 17-71, sin embargo, ya en la segunda (de la misma Editorial, en 2002), reescrita y aumentada, dedicó tan sólo las pp. 22-57 a estas damas, centrándose principalmente en las esposas de los gobernantes del México independiente.

2 Ramos Escandón et al, 1987.

3 Archivo General de Indias (AGI), México, 77, R. 2, N. 27, f. 2. Don Ginés Morote al rey, México, 3 de julio de 1663. Según el diarista Guijo, este señor, fue en la misma flota que los marqueses de Leiva, tras ser designado oidor de la Audiencia de Guatemala y juez de residencia del duque de Alburquerque, virrey saliente. Véase su texto en Documentos, 1853-1854, T. I, p. 444. También se encuentra la obra de este autor por separado como Guijo, 1953. 
su familia, quienes, desde su arribada al territorio novohispano, no habían hecho más que despertar una franca antipatía y repulsa por parte de la mayoría de sus habitantes. Pero, ¿quién era esta mujer tan criticada y en qué contexto se efectúa dicha declaración?

\section{Orígenes nobiliarios, casamiento y descendencia de esta gran dama}

Doña Mariana Isabel de Leiva y Mendoza, llamada así por su abuela paterna (Mariana), y una tía abuela (Isabel), ${ }^{4}$ había nacido el 25 de mayo de 1617 en Madrid, ${ }^{5}$ siendo la hija única del matrimonio de don Sancho Martínez de Leiva y Mendoza, XX señor de la casa, villa y estado de Leiva, primer conde de Baños en 1621, creado marqués de Leiva en $1633,{ }^{6}$ y de la marquesa doña María de Mendoza y Bracamonte, su mujer, condesa viuda de Añover de Tormes. ${ }^{7}$ Nuestra biografiada era pues, por propio derecho, segunda marquesa y XXI señora de la Villa y Casa de Leiva, segunda condesa de Baños. ${ }^{8}$

Como ha venido siendo habitual entre los miembros de la nobleza, y casi a lo largo de toda la Historia, su matrimonio fue acordado ya que la orientación de los hijos estaba condicionada por la planificación e intereses familiares. Aún considerándose lo forzado de dichas uniones, en ocasiones los novios podían encajar bien y vivir una vida amorosa normal; pero en otros muchos casos, el enlace matrimonial no pasaba de un mero contrato entre las partes y el marido se limitaba a cumplir con su esposa para conseguir la sucesión familiar. ${ }^{9}$ El elegido en esta circunstancia fue el primo segundo de la condesa de Baños, don Juan de la Cerda, V marqués de Leiva y de Ladrada. ${ }^{10}$, celebrándose ese matrimonio en Madrid el 20 de febrero de $1632 .{ }^{11}$ A la novia le faltaban aún unos meses para los 16 años y él acababa de cumplir los 28 .

4 Sáenz Berceo, 1997, pp. 136 y 137.

5 Ibidem, p. 94.

6 Fernández de Béthencourt, 2003, T. V, p. 360.

7 Ibidem, pp. 360 y 361; Sáenz Berceo, 1997, p. 98 y http://www.geneall.

8 Fernández de Béthencourt, 2003, T. V, p. 360 y Núñez y Domínguez, 1950, p. VII.

9 Fernández Álvarez, 2002, p. 120.

10 Nacido en Alcalá de Henares en 1604. Era comendador de Alcuesta y trece de Santiago, gentilhombre de cámara del rey sin ejercicio. Fernández de Béthencourt, 2003, p. 360; Sáenz Berceo, 1997, p. 95 y http://www2.uah.

11 Fernández de Béthencourt, 2003, p. 361. 
Frutos de dicha unión fueron varios hijos, nacidos igualmente en la villa y corte: don Pedro, don Gaspar, doña Úrsula y don Antonio. Desde su adolescencia, el primogénito dará más de un disgusto a sus progenitores. Era un joven alocado y despilfarrador. Lo casaron pronto — con 21 años-, con doña María de Alencastre ${ }^{12}$ Sande y Padilla — de 15-, creyéndose que así, quizás, se apaciguaría su ánimo rebelde.

En 1660, don Juan de la Cerda fue designado virrey de la Nueva España. ${ }^{13}$ Toda la familia se debió sentir muy honrada con dicha designación, y entre éstos, doña Mariana Isabel. Desde su enlace, muy joven entonces, había respondido puntualmente a las pautas sociales y religiosas establecidas, dando a su esposo un número de hijos varones que aseguraban la continuidad de la estirpe. Era ya - como comprobaremos a lo largo del texto - una mujer madura — iba a cumplir los 44- y su intransigente y altanero carácter se había ido reforzando con el transcurso de los años, máxime siendo hija única y heredera de su casa; ahora, como virreina, ${ }^{14}$ pretendió convertirse, al lado de su consorte y de forma efectiva, en las más altas autoridades en el territorio novohispano ya que, debido a la gran distancia que los separaba de la metrópoli, estos gobernantes gozaban de la confianza real ostentando amplios poderes. ${ }^{15}$ No olvidemos que a ellos, los virreyes, les serían debidos los mismos respetos y ceremonial que al monarca, como ser recibidos bajo palio, el derecho a usar un tiro de seis caballos en el carruaje, ocupar un lugar principal en los actos públicos y morar en una casa con el rango de palacio real. ${ }^{16}$

Bien pudo ser ella la que insistiera a su marido en solicitar que el primogénito, objeto de tantos disgustos y sinsabores, les acompañase en unión de su esposa, doña María de Alencastre. Así, de camino, aparte de intentar alejarle de esa vida desenfrenada en la que se hallaba inmerso en la corte (pretextando como excusa del todo razonable, necesitar una compañía

12 De Lencastre o de Lancaster. Fallecería en Madrid el 11 de abril de 1673, con 34 años, luego debió nacer en 1639. Ibidem, pp. 366 y 367.

13 Fue nombrado en enero y se le notificó el 26 de febrero de 1660. AGI, Escribanía de Cámara, 223C. Información y pesquisa secreta del Juicio de Residencia. Cuaderno impreso donde se refieren los servicios que hizo a su Majestad el marqués de Leyva y de Ladrada, conde de Baños (15 fols.) y Rubio Mañé, 1955, T. I, pp. 151 y 295.

14 La mayoría de los autores la numeran como "décima" virreina, al haberse basado una y otra vez en las pocas crónicas existentes sobre las listas de estas damas. Según nuestras investigaciones, el número anterior de estas importantes señoras en el Virreinato novohispano fue mayor. Israel, 1996, p. 262 y Rubio Mañé, 1955, T. I, p. 275.

15 Latasa Vassallo, 2002, pp. 115-130, p. 116 y Torre Villar: Advertencias, p. 289.

16 Escamilla González, 2005, p. 379 y Torres Arancivia, 2006, p. 58. 
femenina, que la asistiera en tan larga y dura travesía, por encontrarse, además, en avanzado estado de gestación, casi próxima a dar a luz), ${ }^{17}$ trataba de salvaguardar el patrimonio familiar, al tener así a ese hijo más vigilado.

Esto contradecía la costumbre establecida desde fines del XVI y, por lo tanto, el Consejo de Indias determinó que se nombrase otro virrey. Pero Felipe IV, "muy a favor en esta elección", ${ }^{18}$ resolvió parcialmente lo que pedía don Juan de la Cerda, autorizando que les acompañara el primogénito y la nuera, además de sus otros dos hijos varones, y quedara en España la hija. ${ }^{19}$ Es posible que ese debate con el Consejo de Indias provocara la drástica prohibición, posterior en unos meses a este nombramiento virreinal, dada en Madrid el 11 de abril de 1660, de que los vicesoberanos de México y Perú no llevasen a sus descendientes directos, "aunque sean menores de edad", yernos ni nueras. ${ }^{20}$

\section{Las circunstancias del viaje y la entrada en la capital novohispana}

Partieron de Cádiz, ${ }^{21}$ con una comitiva de cien personas, ${ }^{22}$ el 3 de mayo de 1660. La señora virreina debió de llegar maltrecha por el largo camino hasta tierras andaluzas, lo que, sumado al trajín del embarque y los usuales traqueteos del barco, hizo que diese a luz un niño en alta mar, el 6 de mayo, ${ }^{23}$ tan sólo tres días después de haber levado anclas.

17 Cuando fue nombrado virrey, el marqués alegó que se embarcaría más tarde pues su esposa se encontraba embarazada de seis meses. Un poco más adelante, don Luis Méndez de Haro, y por orden del rey, le indicó que convenía a su real servicio que se incorporase en la flota que estaba próxima para salir ya que en la Nueva España se vivía una situación muy tensa por la enemistad del virrey duque de Alburquerque con el arzobispo. Schäfer, 1947, T. II, p. 24 y 500 años de México.

18 Schäfer, 1947, T. II, p. 24.

19 Fernández de Béthencourt, 2003, p. 364.

20 Confirmada luego, en 1663, y mandada recopilar por Carlos II y la reina gobernadora en 1680, lo cual nos ratifica que no se cumplía. Recopilación de leyes de los Reynos de Indias, I, Libro III, Título III, ley 12, en Rubio Mañé, 1955, T. I, p. 116 y Sigaut, 2002, p. 272.

21 Los virreyes de la época de los Austrias salían desde esta ciudad. Latasa Vassallo, 2001, p. 208.

22 Al pertenecer la mayoría de dichos gobernantes a la nobleza de primera clase en España, contaban con pequeñas cortes particulares que los seguían cuando viajaban a Indias. Torres Arancivia, 2006, pp. 73 y 74 .

23 Ya antes de zarpar era consciente del riesgo a que se exponía, "según el dictamen y parecer de los médicos, por haber de ejecutar la partida en los meses mayores de su preñado y embarcarse para parir en el mar desconocido, como sucedió”. Papel en que se refieren los servicios que hizo a su majestad el conde de Baños..., Hanke, 1978-1980, T. IV, p. 232, y Documento, 1853-1854, T. I, p. 444. 
La navegación continuó sin alteraciones dignas de mención, avistándose las costas mexicanas y arribando la flota frente a la ciudad de Veracruz a mediados de agosto. El domingo 19 por la mañana, se hizo público en la urbe capitalina la llegada de las naves, comenzando a repicar festivamente las campanas de la catedral por espacio de dos horas, extendiéndose los repiques a las iglesias conventuales, y así continuaron también al mediodía y durante la noche. Todavía dichos tañidos se siguieron repitiendo "en los días adelante, a todas horas, en la catedral". ${ }^{24}$

El virrey saliente, el duque de Alburquerque, y su familia dejaron el palacio donde habían residido, ${ }^{25}$ para que éste fuera limpiado y remozado, aguardando la llegada del nuevo inquilino.

Mientras tanto, tras el desembarco, Veracruz fue la ciudad que acogió a los marqueses de Leiva, familiares y séquito. Allí, como solía ser habitual, descansaron unos días, reponiéndose de la dura travesía. El trayecto, hasta llegar a la capital, siempre se hacía por el llamado Camino Real, atravesando una serie de poblaciones (Tlaxcala, Puebla de los Ángeles, Cholula, Huejotzingo, Apa, Otumba, Chapultepec...), donde sus habitantes recibían y agasajaban con grandes celebraciones a los nuevos vicesoberanos. ${ }^{26}$

El jueves 16 de septiembre de 1660, la virreina saliente (duquesa de Alburquerque), acompañó a la marquesa de Leiva desde el convento de Santa Ana, donde habían estado hospedados, hasta el palacio virreinal. ${ }^{27}$ Siguiendo pues un estricto protocolo, la nueva virreina se adelantaba para conceder todo el protagonismo a su esposo y esperar, junto al resto de las señoras nobles locales - en ese intento de afabilidad que se le asignaba hacia las damas principales—, ${ }^{28}$ su entrada pública en la ciudad, que había

24 Idem.

25 Se fueron a las casas de don Prudencio de Armenta, enfrente de San Francisco. Documento, 1853-1854, T. I, p. 445.

26 En Cholula, aún antes de tomar posesión su marido del mando, la marquesa-condesa comenzó a dar señales de ese autoritarismo que la caracterizaba y que igualmente transmitía a sus hijos, pues al conocer que Diego Sánchez de Coca, dueño de obraje de tejer paños, tenía cantidad de negrillas esclavas, fue a escoger algunas para incorporarlas a su servicio. Aunque el tal Diego Sánchez y su esposa, Isabel de la Cruz, hicieron las diligencias oportunas para evitarlo, "le sacaron contra su voluntad con la mano y poder superior que tenía dicha marquesa y sus hijos...dos piesas de esclavas que eran niñas y las traxo a esta ciudad, disiendo las avía menester para ymbiar a su hijo". AGI, Escribanía de Cámara, 223A. Información y pesquisa secreta del Juicio de Residencia, Pieza 2. a ..., f. 6v.; 500 años de México; Hanke, 1978-1980, T. IV, p. 217 y Rodríguez Moya, 2005, p. 68.

27 Idem. y Curiel, 1997.

28 Latasa Vassallo, 2002, p. 118 y Baena Zapatero, 2008, p. 828. 
sido adornada y decorada con construcciones efímeras de complicados programas iconográficos, además de obsequiarles con tres días de fiestas, que incluían banquetes, bailes, juegos, corridas de toros, representaciones teatrales... Llama la atención el hecho de que el diarista Guijo apunte que el nuevo virrey llegaba sin "su hijo heredero", ${ }^{29}$ cuando fue expresamente solicitada su inclusión en el cortejo - junto con su esposa, como ya hemos comentado-, siendo además un joven que seguirá dando mucho que hablar en la capital mexicana, debido a sus desórdenes y tropelías.

\section{La señora virreina, entre lo religioso y lo profano}

El martes 14 de junio de 1661, debido a que "la seca era de las mayores que se habían reconocido, y se caía muerto el ganado, y...secado las acequias y pozos por no haber llovido...", ${ }^{30}$ se trajo en procesión a la Virgen de Los Remedios desde su ermita ${ }^{31}$ a la catedral. El domingo 3 de julio se comenzó otro novenario, asistiendo el virrey y la virreina todas las tardes. La anterior al regreso de la imagen, la marquesa de Leiva, dicen, que le hizo entrega de "una sarta de perlas, de estimación". ${ }^{32}$

En octubre, concretamente el día 5, los mercedarios colocaron en su templo una imagen de talla de más de media vara de alto, de la advocación de Nuestra Señora de Copacabana, ${ }^{33}$ que por cláusula de testamento les había dejado don Antonio de Ulloa, presidente de la Audiencia de Guadalajara, y para ello levantaron tres altares en la calle, "de mucha costa y curiosidad", asistiendo la condesa de Baños a la misa y sermón. ${ }^{34}$

Doña Mariana Isabel, al igual que la mayoría de las virreinas novohispanas, fue una visitante asidua de los monasterios femeninos, sobre todo

29 Sin embargo, más adelante, y en otro pasaje de su crónica rectificará: “...don Pedro de Leiva, hijo mayor y heredero del virey (sic) conde de Baños...”. Documentos, 1853-1854, T. I, pp. 447 y 468 .

30 Ibidem, p. 460.

31 En julio de 1528 ya se hacía mención de dicha ermita, con motivo de la merced que se hizo a Alonso de Villanueva. Alamán, T. II, p. 273.

32 Documentos, 1853-1854, T. I, p. 461.

33 La península de Copacabana se adentra en el lago Titicaca, acercándose a las islas del Sol y de la Luna, antiguos lugares sagrados de los Incas. Esta imagen de la Virgen fue humildemente entronizada en una iglesia de adobe y piedras el 2 de febrero de 1583, lo que hace de este santuario mariano uno de los más antiguos del Nuevo Mundo. Su devoción se fue extendiendo poco a poco por todo el continente americano. http://www.corazones.

34 Documentos, 1853-1854, T. I, p. 471. 
del de carmelitas descalzas de Santa Teresa ${ }^{35}$ acudiendo allí "a todas horas y tiempos"36, incluso en ocasiones con su esposo, a visitar a una profesa denominada madre María de Santa Inés, a quien la virreina apoyó decididamente para su elección como abadesa y que, como nos indica el cronista Guijo, ${ }^{37}$ cuando salió electa, negó su obediencia al arzobispo, solicitando pasar bajo la dirección de los carmelitas varones, hecho que venía siendo reiterado desde la fundación del monasterio. Como en circunstancias anteriores, tampoco ahora se logró dicha pretensión, ${ }^{38} \sin$ que sepamos exactamente qué papel jugó doña Mariana Isabel en este proceso posterior a la alternativa por el máximo cargo del citado cenobio carmelita.

El 25 de mayo de 1662, fue un día importante para la condesa de Baños, al cumplir 45 años. Se le "hicieron grandes fiestas en palacio, y las personas de caudal la regocijaron con libreas y carrozas nuevas y cadenas de oro al cuello, para darle los días;...convidóse a todas las damas y señoras del reino que fueron a palacio costosamente aderezadas", ${ }^{39}$ pues, como especificaba Thomas Gage: "gastan extraordinariamente en vestir y sus ropas son por lo común de seda", además del uso desmedido en piedras preciosas y perlas..$^{40} \mathrm{Se}$ había echado a suertes entre los asistentes, todos ellos "personas de caudal", quién debía de aportar capital para dicha celebración, saliendo electo don Anastasio Coronel Salcedo Benavides, alcalde mayor de Metepec, ${ }^{41}$ que entregó una importante suma de ducados. Disfrutaron además de la representación de una comedia, en la que actuaron los criados y criadas de los virreyes. ${ }^{42}$

En relación con la procesión del Corpus, el 8 de junio de 1662, se generó una grave tensión, entre el virrey y el Cabildo eclesiástico, por cau-

35 Fundado en 1616 por monjas concepcionistas provenientes del monasterio de Jesús María, igualmente establecido en la capital. Dicha orden seguía la vida particular, más cómoda y relajada; en cambio las carmelitas, según la reforma de Santa Teresa de Jesús, cumplían el voto de pobreza y practicaban la denominada vida común. Arenas Frutos, 1990 y Ramos Medina, 1990, pp. 49-63.

36 Documentos, 1853-1854, T. I, p. 463.

37 Idem.

38 Era un tema que, como indicamos, se venía discutiendo desde la fundación y que durante el gobierno eclesiástico de López de Ancona, en 1653, al parecer, se había conseguido. Desgraciadamente, este arzobispo falleció antes de enviar su consentimiento a España. Ramos Medina, 1990, p. 95.

39 Documentos, 1853-1854, T. I, p. 482.

40 Maza, 1968, p. 21; Sáenz de Santa María, 1971, http://cvc.cervantes.

41 Su generosa donación obtuvo muy pronto resultados. El miércoles 31 de mayo de 1662, seis días después de dichos agasajos, se le remuneró espléndidamente al ser nombrando nada menos que corregidor de la ciudad de México. Rubio Mañé, 1955, T. I, p. 277.

42 Documentos, 1853-1854, T. I, pp. 482 y 483. 
sas al parecer triviales, instigada, según cuentan y recuentan crónicas y leyendas, por doña Mariana Isabel. Este cortejo solía recorrer el trayecto que iba por la calle de Tacuba, pasando por las de Santa Ana y acabando en la de Santo Domingo. En esas fechas, la marquesa se encontraba delicada de salud - posiblemente los comienzos de su nuevo embarazo, del que luego abortó, como después comentaremos-y, deseando presenciar dicho desfile religioso, insistió a su esposo para que cambiara el itinerario y lo entrara a la plaza mayor - actual Zócalo- por la calle de San Francisco, en lugar de la de Santo Domingo. Aunque el virrey, al principio, tuvo serias dificultades con el Cabildo eclesiástico, fue obedecido y regresó la procesión por las citadas calles. Pasó en efecto por delante del palacio virreinal, en cuyo balcón principal, llamado especialmente "de la virreina" ${ }^{43}$ se hallaba doña Mariana Isabel, acompañada de sus damas; siguió por la calle del Reloj y entró a la catedral por el cementerio. ${ }^{44}$ Con estas demandas, que traerían más problemas y críticas al conde de Baños, demostraba la virreina que estaba acostumbrada a conseguir sus deseos.

El Cabildo catedralicio presentó duras quejas contra el virrey, protestas que fueron escuchadas en la Corte, desaprobándose su conducta; Baños fue condenado a pagar una multa de 12.000 ducados y se ordenó terminantemente que no se volviera a alterar el trayecto de dicho cortejo procesional. ${ }^{45}$

Debía ser la virreina aficionada a las obras teatrales, al igual que su esposo, pues el domingo 11 de junio de 1662, infraoctava de Corpus, en que se pensaba representar otra comedia en el teatro del cementerio de la catedral, según costumbre, se ordenó que se realizara en el patio de palacio, en donde estaba la pila, para que ella y sus criados asistiesen a la representación, al estar de nuevo embarazada. A los pocos días, sin embargo, "le sobrevino... un desconcierto peligroso...y malparió" ${ }^{46}$

43 Maza, 1968, pp. 64 y 65; Rodríguez Moya, 2005, p. 28 y Escamilla González, 2005, p. 387.

44 Romero de Terreros, 1944, pp. 28 y 29.

45 Ya en el Corpus del año 64, aunque "pretendió el virrey y su mujer que fuese la procesión a palacio", no se consiguió, asistiendo la virreina a ella desde las casas de Francisco de Córdoba, contador mayor, hecho que llegó a comprometer el honor del virrey. Documentos, 1853-1854, T. I, pp. 483484 y 526; Baena Zapatero, 2008, pp. 828 y 829 y Valle-Arizpe, 2000, pp. 79-82.

46 En las sentencias del Juicio de Residencia del marqués se mencionan “...las continuas asistencias en todo el tiempo de su gobierno a las comedias que públicamente se representaban...casi todos los días de fiesta..., como cualquiera vecino particular". En ocasiones, llegó a afirmar en público que una obra era "muy buena y yo la e visto representar en Madrid". AGI, Escribanía de Cámara, 223A. Información y pesquisa secreta del Juicio de Residencia, Pieza 2. ${ }^{a} .$. , fs. $91-92$ y 133 v. Hanke, 19781980, T. IV, p. 219 y Documentos, 1853-1854, T. I, p. 486. 


\section{Una "débil salud de hierro". Máximas honras para la virreina y tristes acontecimientos familiares}

A partir de dicho aborto, los achaques y padecimientos que le sobrevivieron a doña Mariana Isabel fueron constantes. Cuando ya parecía hallarse algo recuperada "le volvió a repetir el desconcierto" y fue tan grave el susodicho ataque, que incluso le llegaron a administrar la extremaunción el domingo 30 de julio a las cinco de la tarde. Se organizó para ello una procesión, a la que acudieron las religiones y sus prelados, el virrey, la Audiencia y todo el reino. Las campanas de la catedral repicaron durante el tiempo que duró dicho ceremonial "en la forma que se acostumbra para sacramentar a los prelados", asistiendo igualmente todo el Cabildo eclesiástico, con sobrepellices, y la capilla. Le administró el sacramento el doctor Simón Esteban, canónigo magistral. ${ }^{47}$ Pero como la señora no se recuperaba, es más, "fuésele aumentando la enfermedad...y llegó a lo último", ${ }^{48}$ llevaron al palacio todos los santos de devoción, entre ellos una imagen de la Asunción, de talla y cuerpo entero, a la que tenían los naturales gran fervor, propiedad de la iglesia de Santa María la Redonda, administrada por los franciscanos. ${ }^{49}$

En esa marcha procesional donde se dieron cita las más altas personalidades de la ciudad, muchos se encontraban a disgusto, no queriendo manifestar su contrariada actitud, pero criticaron después el "mal gobierno del virrey y de la mucha mano que tiene en todo la virreyna... pareciéndoles tendrían algún reparo los daños que se padecen y se atribuyen por mayor a la virreyna". ${ }^{50}$

La marquesa, en contra de todo pronóstico, milagrosamente mejoró y para regresar la imagen a su casa, el lunes 14 de agosto, se instaló en los corredores altos de palacio un altar adornado de mucha plata y cera, cantándose allí misa mayor. Ese mismo día, a las tres de la tarde, salió de la

47 Fue uno de los eclesiásticos mexicanos más distinguidos del siglo XVII. Era de los mejores oradores sagrados de su tiempo y frecuentemente los virreyes le solicitaron su dictamen en los negocios más arduos. En tres ocasiones fue, además, rector de la Universidad. Rubio Mañé, 1955, T. I, pp. 278 у 279.

48 Documentos, 1853-1854, T. I, p. 488.

49 Sigaut, 2002, p. 271.

50 AGI, México, 77, R. 2, N. 27, f. 2. Don Ginés Morote al rey. Aunque él llega a dudar incluso del propio marqués al afirmar que "aunque yo he dicho siempre que si el virrey tuviera buenos lados, por ser buenas sus entrañas...me parecen tienen raçón los que dicen que es malicia disimulada...lo que yo veo es que si los oydores están intimidados e impacientes, algo más lo estarán los particulares, que no tienen adónde recurrir...". México, 3 de julio de 1663. 
residencia virreinal la procesión llevando en hombros los frailes de San Francisco a la Virgen, portando luminarias los hijos del virrey y sus criados y yendo él mismo detrás de la imagen acompañado de toda la nobleza, Audiencia y religiones (excepto la del Carmen). El cortejo fue por la calle de San Francisco hasta Santa Isabel, en cuya iglesia entró, y después en la de la Concepción y de allí a la suya de Santa María la Redonda, repicando todas las campanas de dichos templos. El acto acabó pasadas las seis de la tarde..$^{51}$

Es lógico que durante esos quince días en que la virreina tuvo la venerada imagen tan cercana, el palacio virreinal donde residían el virrey y su familia, y especialmente la condesa tan delicada de salud, se convirtiera en el núcleo de la vida social, política, e incluso religiosa, de la ciudad de México.

El lunes 21 de agosto, salió de la capital la virreina, aparentemente "con intento de mudar de temple...por la gravísima enfermedad que padece...de que está desahuciada de los médicos", ${ }^{52}$ pero también la situación allí, como veremos, contra ella y sus hijos, se había vuelto muy tensa y quizás, además de buscar la tan ansiada mejoría, decidió alejarse para que los ánimos se calmasen. Marchaba a la villa de Tacubaya, y en concreto a la huerta de don Austacio de Salcedo, corregidor de esta villa, y al seguirla un nutrido séquito de personas, no se les ocurrió otra medida que confiscar "todas las huertas a sus dueños...y casas de dicho pueblo", para ser utilizados por, prácticamente, toda la corte virreinal, ya que tanto su esposo, como los hijos, nuera, y demás criados..., también se le unieron, dejando casi desocupado el palacio. ${ }^{53}$

Aunque tres meses más tarde, el 25 de noviembre, algo recuperada de sus dolencias, acudió en compañía de sus damas "y con bastante ceremonia", de nuevo a Santa María la Redonda en acción de gracias. Doña Mariana Isabel se pasó en este retiro casi un año -mientras el virrey iba y venía de México a Tacubaya-. Tuvo que regresar apresuradamente a la

51 Documentos, 1853-1854, T. I, pp. 487-489.

52 En el que más confianza depositaron los virreyes fue en el doctor don Gabino Farina. En agradecimiento a sus cuidados e inicios de recuperación de doña Mariana Isabel, le nombraron juez del pulque, llevando éste dicha comisión “...con tanta privación que no se obraba más de lo que él quería, dando las licencias para venderlo y acarrearlo". Eso le generó importantes ganancias, al existir una gran demanda para la venta de dicho producto. AGI, Escribanía de Cámara, 223A. Información y pesquisa secreta del Juicio de Residencia, Pieza 2. a ..., fs. 118 y 166v. Israel confunde su nombre de pila (Gavino, con "v", en la documentación), con su apellido y lo cita como "Pavino". Israel, 1996, p. 262.

53 Rubio Mañé, 1955, T. I, p. 279. 
capital el sábado 21 de julio de 1663, debido a dos importantes noticias: una, un aviso llegado de Campeche sobre una escuadra de galeones enemigos y otra, la comunicación del fallecimiento del arzobispo don Mateo Sagade Bugueiro. ${ }^{54}$ Pronto insistió de nuevo la virreina en marchar fuera de la urbe, ahora a Cuernavaca, para seguir recobrando su vigor, aunque el propio Guijo afirma: "dicen de tener otras nuevas de las que se han dicho" ${ }_{55}^{5}$ como después comentaremos.

Además de las complicaciones de su delicada salud, a doña Mariana Isabel le acompañaron luctuosos sucesos durante su estancia en la Nueva España. El primero de ellos, el fallecimiento en menos de tres horas, el 11 de agosto de 1661 — apenas al año de llegada al territorio-, de la hija de su primogénito don Pedro de Leiva y de su esposa doña María de Alencastre que, según el cronista Guijo, tenía dos años y medio de edad, siendo enterrada en Santa Teresa, el monasterio carmelita tan vinculado con la familia. ${ }^{56}$ Esa niña debió de nacer, por tanto, en torno a febrero de 1659 , e iría a México con un año y unos tres meses. Nos resulta muy curiosa la alusión que se hace de la nuera de la virreina años después, ya en la metrópoli, al morir de sobreparto por el nacimiento de otra hija, indicándose tras "una esterilidad de casi veinte años" ${ }^{57}$ cuando también había dado a luz un varón el 9 de agosto de 1663 en ese retiro campestre de Tacubaya, aunque este niño fallecería igualmente pronto, el martes 6 de mayo del año siguiente (1664), a punto de cumplir los nueve meses. Con gran acompañamiento de carrozas llevaron su cuerpo al convento de religiosas de San Juan de la Penitencia, donde lo depositaron los frailes franciscanos. ${ }^{58}$

Pero, más dramática si cabe, fue también para nuestra virreina la defunción de su pequeño vástago, nacido en alta mar, al venir a tierras mexicanas, que también murió en Tacubaya, el viernes 3 de agosto de 1663, a las cuatro de la madrugada. Se enlaza, casi a la vez, la muerte con una nueva vida, también efímera; fallecimiento y nacimiento de hijo y nieto, casi al mismo tiempo. El cronista Guijo indica que ese hijo "tercero" en realidad, era el cuarto-, había enfermado y que, aunque los médicos hicieron lo posible, no tuvo remedio. Tenía este niño tres años y tres meses

54 Quien había fallecido en la ciudad española de Cartagena. Bravo Ugarte, 1940, p. 39.

55 Documentos, 1853-1854, T. I, p. 517.

56 La consternación fue tal, que se suspendió por algunos días la fiesta del Pendón y San Hipólito, hasta el domingo 21 de agosto, en que se celebró con vísperas y día en la forma ordinaria. Documentos, 1853-1854, T. I, p. 468 y Rubio Mañé, 1955, T. I, p. 276.

57 Fernández de Béthencourt, 2003, p. 367.

58 Rubio Mañé, 1955, T. I, p. 279. 
-recordemos que había nacido el 6 de mayo de 1660_- Lo trajeron a la ciudad en una carroza, a cortina cerrada, disponiendo que el entierro se hiciese dentro del convento de religiosas franciscanas de San Juan de la Penitencia (donde, como acabamos de comentar, apenas nueve meses después, sería también depositado el cuerpo del nieto, segundo hijo de Don Pedro de Leiva), asistiendo casi "todo el reino a la novedad". ${ }^{59}$ En el siglo del barroco, la escenografía alrededor de la muerte no quedaba fuera, incluso en estos duelos de niños, y podemos comprobar cómo esos cortejos mostraban la representación y la etiqueta características de la época.

Tristes recuerdos le debieron quedar tanto a doña María de Alencastre, nuera de la virreina, como a ésta misma, del enclave de Tacubaya, e incluso de las tierras mexicanas, habiendo dejado allí la memoria de sus pequeños hijos; desdichas acaecidas a esta familia en un corto lapso de tiempo; pero tampoco hemos de olvidar que, aunque entre las elites el nacimiento fuera considerado un elemento central, la muerte de los infantes no tenía la trascendencia de hoy en día, por ser, desgraciadamente, bastante común por entonces. ${ }^{60}$

\section{“Dimes y diretes” en el entorno virreinal. Graves críticas a doña Mariana Isabel y a sus hijos}

Aunque el mandato del conde de Baños no contó con hechos eminentes e incluso algún historiador se arriesga a calificarlo "de funesta memoria" ${ }^{1}$ y "muy poco brillante", los jesuitas, el bando burocrático y los frailes en su mayoría, alabaron su gestión, ${ }^{62}$ llegando todos a coincidir en que "...los escándalos que la conducta de su familia produjo en la colonia"63 y, sobre todo, "...las mosedades (sic) del señor don Pedro", ${ }^{64}$ al que se unió a veces su hermano don Gaspar, "...le acibaraban la vida", ${ }^{55}$ llegando inclu-

59 Documentos, 1853-1854, T. I, pp. 517 y 518.

60 De Paz Sánchez y Hernández González, 2000, p. 70.

61 Así lo describe el versado Schäfer. Hanke, 1978-1980, T. IV, p. 181. y Tateiwa, http://syutin. El propio título de un reciente artículo de Pierre Ragon, en el AEA anterior a éste, también de 2010, nos confirma sus "pasos en falso".

62 Como fueron los religiosos Alegre, Vetancurt y Cavo, quienes lo apreciaron por la actitud tan favorable que demostró hacia ellos. Israel, 1996, p. 262.

63 Riva Palacio, 1968, T. II, p. 324. Rubial García, 2005, p. 123.

64 Vetancurt, 1960, T. II, p. 222.

65 Cavo, 1852, p. 102 y 1949, p. 334. 
so a advertir la propia Audiencia de cómo se debía “...cuidar de la juventud de los hixos del marqués", ${ }^{66}$ quienes se desplazaban en carrozas de seis mulas, "como lo avían echo todo el tiempo que governó (su padre)" resultando impensable en una corte virreinal en la que todo estaba marcado por las normas al "... ser indecente el que andubiesen iguales los coches de sus hixos, por no ser permitidos más que a ellos (los virreyes)" ${ }^{67}$ En ocasiones, incluso llegaron a organizar carreras con dichos carruajes, viéndose a don Pedro "yendo por cochero de el principal...causando...mucha notta y escándalo". ${ }^{68}$

Ese primogénito que desde sus años de juventud había sido tan difícil de vigilar, como ya antes apuntábamos, dejó amargo recuerdo en la Nueva España. Desde la misma llegada del conde de Baños, en Chapultepec, don Pedro de Leiva había comenzado a dar pruebas de ese carácter altanero que le caracterizaba. Se enfrentó allí con el criollo don Fernando de Velasco, tercer conde de Santiago Calimaya ${ }^{69}$ y yerno de don Diego de Villegas, al haber ofendido duramente a los nacidos en Nueva España, hablando despectivamente de ellos. A partir de esa fecha, surge una rivalidad enconada entre ambos; el de Leiva, matando incluso a un criado muy querido del noble y, ya al final del mandato virreinal de su padre, llegaron a desafiarse, teniendo que mediar el arzobispo, don Diego Osorio de Escobar, quien zanjó la cuestión, recluyéndolos a ambos en sus casas con 2.000 ducados de multa a cada uno. ${ }^{70}$

También tuvo que intervenir dicha autoridad eclesiástica al concurrir habitualmente ambos hermanos al convento de religiosas de Regina Coeli, a visitar a una joven novicia "que se entiende se llama Nicolasa", con la excusa de que "...les diese música, por ser diestra en ella”. Uno y otro llegaron a reñir, "sobre quál le avía de hablar y sacado las espadas", afirman-

66 AGI, México, 77, R. 3, N. 33, f. 8. México, 21 de julio de 1664. La Real Audiencia al rey.

67 Ibidem, f. 6. Ver nota 16.

68 AGI, Escribanía de Cámara, 223A. Información y pesquisa secreta del Juicio de Residencia, Pieza 2. ${ }^{\mathrm{a}} \ldots$, f. $30 \mathrm{v}$.

69 El condado de Santiago de Calimaya fue otorgado por Felipe III, en 1616, a Fernando de Altamirano y Velasco (criollo) y a su madre, Mariana de Ircio y Velasco, por los servicios de su padre y esposo, el dos veces virrey de Nueva España Don Luis de Velasco, denominado el Joven o el Mozo, que recibió el título de marqués de Salinas del Río Pisuerga, zona donde había nacido su padre, el segundo virrey novohispano Luis de Velasco, el Viejo. Ladd, 1984, p. 305; Sarabia Viejo, http://www.rah. y http://es.wikipedia.

70 Noveno obispo de Puebla de los Ángeles, que no aceptó el Arzobispado de México, pero que sustituyó al virrey durante dos meses y veintisiete días hasta la llegada del sucesor marqués de Mancera. Bravo Ugarte, 1940, p. 47; Documentos, 1853-1854, T. I, p. 546 y Riva Palacio, 1968, p. 324. 
do don Pedro que “...tenía dispuesto rovarla”. El prelado envió al monasterio a don Francisco Rafael del Villar, su asistente, para que recriminara a la prelada lo mal que había hecho en "dejar salir a hablar en el locutorio a aquella muchacha" y, para acallar los malintencionados rumores, "...se le dio la profesión". ${ }^{71}$

Aunque estaban prohibidos los juegos públicos y se había encargado especialmente al virrey perseguir a los transgresores, parece que, en el cuarto del palacio que ocupaba don Pedro había reuniones todas las noches, donde se entablaban distintos juegos de naipes. Se mandaban invitaciones y recados personales con las criadas y otras personas y, a quien no asistía, se le enviaban amenazas. Por este cargo se impuso al conde de Baños una multa de 4.000 pesos. $^{72}$

Además, los dominicos acusaron igualmente a don Pedro de haberles exigido 1.000 pesos para que no se les quitase el servicio personal de los indios, en los pueblos y doctrinas que tenían asignados, en un claro abuso del poder paterno. ${ }^{73}$ Éste llegó a tener

"tan ajada a la gente de todos estados (que) en viéndole por alguna calle divertían su camino o se entraban en alguna casa por no encontrarle, por evitar algún disgusto", escondiéndose y “...hechándole muchas maldiciones”.

Ello era debido a que se había convertido en un personaje desgraciadamente célebre, al haber sido

"tantos sus arrojos, que los tuvo con muchas mujeres casadas con personas de importancia, entrando en sus casas...solicitándolas...de que resultaron escándalos, heridas

71 Racionero de Puebla, de unos cuarenta años, que asistía al arzobispo. Conoció al conde de Baños entre 1647-1653, "que este tiempo estubo en los Reynos de España, en la villa de Madrid". AGI, Escribanía de Cámara, 223A y 223B. Información y pesquisa secreta del Juicio de Residencia, Piezas 2. ${ }^{\text {a }}$ y $3 .^{\mathrm{a}} \ldots$... fs. 16 y 16v. y 36, respectivamente y Sigaut, 2002, p. 272.

72 Se establecían hasta "tres y quatro mesas, con que se causaron muchos ruidos y escándalos en todas las familias". Don Rodrigo de Mexía, alguacil mayor del Tribunal de Cuentas de México, en tres noches perdió 47.000 pesos; los condes de Santiago, don Juan y don Fernando Altamirano de Velasco, su hijo, más de 40.000 pesos, y para su paga empeñaron sus haciendas y alhajas, otorgando escrituras para los restos; don Enrique de Ávila, corregidor de México, “...otra cantidad de treinta o cuarenta mill pesos" y don Juan Yrursum otros 30.000 pesos. Y otras muchas pérdidas que hicieron diferentes personas de cuatro, seis, y diez mil y más pesos, que expresan los testigos, llegándose incluso a afirmar que hasta "xugaban los eclesiásticos, como era el doctor Simón Estevan, canónigo magistral...y otros ynfinitos...como el gobernador don Juan de Torres Castillo, don Juan de Prada, difunto, don Pedro Sáens Yzquierdo”. AGI, Escribanía de Cámara, 223A. Información y pesquisa secreta del Juicio de Residencia, Pieza 2. …, fs. 17v., 18 y 160; 500 años de México; Hanke, 1978-1980, T. IV, pp. 218-219 y Sigaut, 2002, p. 272.

73 Hanke, Ibidem, p. 223 y Sigaut, Idem. 
y muertes". Públicamente "se (le) tenía por un hombre desenfrenado". También su hermano don Gaspar, fue cómplice en muchas de estas fechorías, llegando igualmente a ser acusado de galanteador y pendenciero. ${ }^{74}$

Antes estas reiteradas acusaciones el virrey los defenderá, alegando que todo eran habladurías y que, aunque la propia Audiencia ya le había advertido que “...tubiese cuidado en que don Pedro y don Gaspar de Leiba, mis hijos, no saliesen de noche como se desía lo havían hecho...en el tiempo de mi gobierno an estado assistentes en cassa a la oración..., a sus tiempos y oras en mi compañía, con la atención y obediencia que an debido tenerme, conforme a su obligación,... sin embargo de lo que la calumnia a querido introducir en contrario". ${ }^{75}$ Es lógico pensar que la condesa, por encima de todo madre y quizás impulsora indirecta de esas violencias por sus mimos y "tapaderas" pecuniarias, de apoyos y peticiones de perdón, jugó un papel activo en estas tensiones, que traerían problemas a toda la familia Leiva-Baños.

Tantas habían sido las quejas recibidas en el Consejo de Indias, sobre los desmanes y supercherías, especialmente del primogénito, que la Corona decidió enviar a don Francisco de Vallés, oidor de la Real Chancillería de Valladolid en Castilla, quien, además de ir como visitador general de las Cajas de México, llevaba entre otras órdenes y comisiones, la de "enbarcar (sic) al hijo mayor"76 y reenviarlo para España, poniendo "en grande cuidado a los marqueses y a sus hijos, qual nunca tubieron en su gobierno". ${ }^{77}$

A esto, evidentemente "no havía querido el marqués" ceder, e incluso se comentó "públicamente (que) le dieron seis mill pessos, además de sus salarios", ${ }^{78}$ llegando este visitador a estar a partir de entonces "mui uniforme con el virrey y su mujer...", ${ }^{79}$ consultando con éstos "todos los nego-

74 A éste último se le achacaba igualmente, la muerte del caballero don Cristóbal de Montoya, en un enfrentamiento originado "por una mujer casada". AGI, Escribanía de Cámara, 223A y 223B. Información y pesquisa secreta del Juicio de Residencia, Piezas 2. ${ }^{\text {a } ~} 3$ a $^{\mathrm{a}}$..., fs. $133 \mathrm{v} .-134$ y $30 \mathrm{v} .-31$, respectivamente.

75 AGI, México, 39, N. 26. El virrey marqués de Baños a la Real Audiencia. México, 14 de julio de 1664 .

76 Ibidem, N. 18, f. 1. Parece que Don Francisco llegó a la ciudad de Puebla de los Ángeles "vien achacosso". Informe de don Diego de Osorio, obispo de la Puebla, sobre el procedimiento de don Francisco Vallés. México, 20 de julio de 1664.

77 Ibidem, f. 2 y Schäfer, 1947, T. II, p. 25.

78 AGI, México, 39, N. 18, fs. 6-10. Informe de don Diego de Osorio, obispo de la Puebla, sobre el procedimiento de don Francisco Vallés. México, 20 de julio de 1664.

79 AGI, México, 77, R. 2, N. 27, f. 1. Don Ginés Morote al rey. México, 3 de julio de 1663. 
cios", ${ }^{80}$ lo cual nos acerca a una compra de su apoyo. Es más, aprovechó el virrey las noticias de la entrada del enemigo en Cuba y la circunstancia de haber "saqueado la ciudad (de Santiago)", aconsejando "mandar a don Pedro a conducir gente para la Veracruz y que don Gaspar...quedasse en esta ciudad levantando gente..." siendo un pretexto "como lo bió todo el reino...para no ejecutar la cédula" ${ }^{81}$ y también intentando mejorar la valoración de ambos jóvenes con estas acciones positivas.

Pagos y comisiones nada inusuales por parte de los marqueses, para acallar órdenes superiores y granjearse, o mantener, amistades y apoyos, como también ocurrió en el caso de fray Juan de la Torre, obispo electo de Nicaragua, "íntimo amigo del virrey...( y que) se estrechó mucho con los virreyes", apoyándolos en el caso anterior. En agradecimiento, las malas lenguas afirmaron que le habían entregado "diferentes alajas, un coche y grande cantidad de plata labrada, que todo, dicen, importaría doce o catorce mil pesos". 82

Aparte de esa desaprensiva e incontrolada conducta de los hijos varones, tampoco doña Mariana Isabel se vio libre de importantes denuncias y, como anteriormente comentamos, decidió en varias ocasiones alejarse de la ciudad de México e irse a cualquier retiro campestre (Tacubaya, Cuernavaca...) con la familia, poniendo como excusa su salud; nos mostramos en total acuerdo con el cronista Guijo, quien aludía a "otras nuevas", ${ }_{83}$ creyendo que se refería a poder dominar mejor en esos espacios más reducidos a sus vástagos, tratando así de alejarlos de la capital y atenuar, en parte, las habladurías y acusaciones de las que venían siendo objeto. Su traslado a esos lugares atraía a ellos, sin duda, a paseantes, e incluso residentes, de los linajes más destacados de la Nueva España.

A ella se la llega a tachar de intromisión aún en la administración de la justicia ${ }^{84}$ además de que, quien quisiera conseguir algún cargo, debería

80 Ibidem, f. 3.

81 AGI, México, 39, N. 18, f. 4. Informe de don Diego Osorio de Escobar, obispo de la Puebla, sobre el procedimiento de don Francisco Vallés. México, 20 de julio de 1664.

82 Ibidem, f. 3. Se decía que habían surgido disgustos "porque la marquesa no quería dar más de quatro (mil)". México, 20 de julio de 1664.

83 Ver nota 55.

84 AGI, México, 77, R. 2, N. 24, f. 3. “...quando son tan notorias las experiencias, que aún en la administración de justicia, si no es a gusto de la virreina no tiene lugar, ni se atreven los oidores, por las molestias que les hacen, a votar libremente". Don Diego Osorio de Escobar, obispo de la Puebla, al rey. México, 11 de junio de 1663. 
pagarle una buena cantidad, ${ }^{85}$ algo realmente excepcional para la época en la que nos desenvolvemos, al ser mujer; también de tener una afición desmedida por conseguir riquezas y beneficios, habiendo obtenido importantes ganancias en los aprovechamientos y compraventas de sus "paniaguados" y criados en los corregimientos y alcaldías mayores, al igual que con el comercio de Filipinas. Tenemos constancia de que llegó a valerse de insospechados, pero muy directos informantes, que le daban noticias de primera mano, como fue el caso de una criada anciana que el oidor don Francisco de Vallés, llegado como visitador, "trajo de España”, quien iba muchas veces a entrevistarse con la marquesa, y que aún "... siendo persona de poco porte, le daba almoada en su estrado", como era público, ${ }^{86}$ lo que significaba elevarla socialmente al sentarla en medio de las damas y criadas de confianza, que le hacían compañía, a modo de "corte doméstica", a cambio de las noticias oídas, tanto en las casas donde trabajaban, como en las calles.

Incluso se llegó a afirmar que en una partida de plata sin quintar, "asta cantidad de diez mil pessos", que se detectó cerca de la ciudad de México, al ser se entrevistados los supuestos dueños, y descubriéndose que era de la marquesa, temerosos los funcionarios de las posibles represalias que podrán surgir si se la requisaban, "se la (de)volvió". ${ }^{87}$

\section{Ignominiosa salida del Virreinato y regreso a la Península}

El virrey, como sabemos por la documentación y amplia bibliografía existente, tampoco resultó bien parado en los últimos tiempos de su gobier-

85 En el Juicio de Residencia realizado a su esposo, la llegaron a acusar de lo que hoy denominamos "tráfico de influencias", por permitir que "la marquesa de Leiva y sus hijos tuviesen parte en los aprovechamientos, tratos y comercios que sus criados tuvieron en los corregimientos y alcaldías mayores...", siendo público en esta ciudad y en la de Puebla "que tenía negociación la señora marquesa y su hijo don Pedro de Leyba y los de su cassa, en todas las libranzas, situasiones y limosnas que se pagaban de la caxa y que se compraban las libranzas...". AGI, Escribanía de Cámara, 223A.

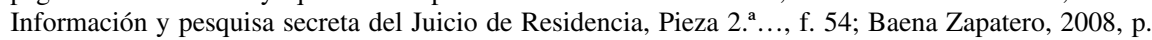
821; Hanke, 1978-1980, T. IV, p. 233 y Sigaut, 2002, p. 271.

86 AGI, México, 39, N. 18, fs. 4 y 5. Informe de don Diego Osorio de Escobar, obispo de la Puebla, sobre el procedimiento de don Francisco Vallés. México, 20 de julio de 1664.

87 Don Francisco Rafael del Villar declaró que había oído decir que la señora marquesa vendió una "muy considerable cantidad de plata por mano de un capitán llamado don Antonio Augustín de Villanueva", remitida "de las minas de Pachuca y Guanajuato, donde tenía dos criados por alcaldes mayores". Ibidem, f. 7 y AGI, Escribanía de Cámara, 223A. Información y pesquisa secreta del Juicio de Residencia, Pieza 2. ${ }^{\text {a }} \ldots$, fs. 95 y 95 v. 
no, debido a estas situaciones familiares (ampliamente denunciadas) y a irregularidades en su gestión, a lo que se unió la gravedad de ocultar documentación oficial remitida desde la Península, incluyendo seis reales cédulas del monarca por las que se le relevaba del mando, nombrándose como sustituto al arzobispo don Diego Osorio de Escobar, ${ }^{88}$ hasta la llegada del nuevo sucesor. Baños se mostró en contra, al igual que sus hijos, viviéndose unos días tensos y difíciles en el gobierno del Virreinato, pero al final, el conde hubo de ceder ante un documento real que le presentó la Audiencia, donde se encargaba del gobierno al organismo de justicia en caso de que el prelado hubiera fallecido o no aceptara el mando. El 29 de junio de 1664, tomó por fin posesión del cargo el arzobispo Osorio de Escobar. ${ }^{89}$ El virrey, una vez conocida su sustitución por el marqués de Mancera, que llegaría en breve, aún osaba amenazar "a todos con el pariente que venía a governar", sobre todo a los que se aventuraron "... a escribir grande copia de sátiras en que con ocasión de culpar acciones del gobierno se atrevieron a decir gravíssimas cosas", hasta que se supo "que es muy prudente" —el marqués de Mancera—, y se fueron tranquilizando los ánimos..$^{90}$

Los marqueses se trasladaron a la casa del doctor don Simón Estevan, canónigo buen amigo suyo, en la calle de Tacuba ${ }^{91} \mathrm{y}$, a partir de entonces y hasta su partida, hubieron de aguantar, como el propio conde indicara: “...vosses, víctores grabes e indignas injurias...". ${ }^{92}$ Incluso, con ocasión de las celebraciones de la llegada del nuevo virrey Mancera, el 8 de octubre de 1665, "el de Baños y su mujer y familia...estando para correr toros, entraron en la plaza y el vulgo comenzó a silbarlos y mofarlos". ${ }^{93}$

El 12 de noviembre, día de San Diego, a las once de la mañana, salió el conde de Baños, con su mujer y demás familiares, para la villa de San Agustín de las Cuevas, a tres leguas de la ciudad, por orden de su juez de residencia. Aunque doña Mariana Isabel había alegado que "el temple le era dañoso a la salud, y pidió por esta causa que fuese su retiro a Tacubaya", por ser un lugar de gran predilección suya, su solicitud no se aceptó. Les acompañó el marqués de Mancera y don Juan Francisco de

\footnotetext{
88 Ver nota 70. Documentos, 1853-1854, T. I, p. 530.

89 Riva Palacio, 1968, T. II El virreinato, p. 326,

90 AGI, México, 77, R. 3, N. 46. Don Ginés Morote al rey. México, 25 de agosto de 1664.

91 Documentos, 1853-1854, T. I, p. 533. de 1664 .

92 AGI, México, 39, N. 26. El virrey conde de Baños a la Real Audiencia. México, 14 de julio

93 Documentos, 1853-1854, T. I, p. 553.
} 
Montemayor y Cuenca, oidor de la Audiencia. Por su parte, la marquesa de Mancera, como exigía el protocolo, escoltaba a la de Baños y su nuera; tan sólo custodiaba a las damas Francisco de Córdoba, contador mayor. ${ }^{94} \mathrm{La}$ salida desde Veracruz para España la realizaron el sábado 8 de marzo de 1666 en la flota a cargo del general don José Centeno. ${ }^{95}$

Ese hijo primogénito aún será motivo posteriormente de graves preocupaciones para la familia. Pensamos que la Corona no deseaba su establecimiento en la corte, habida cuenta de los sucesos ocurridos, temerosa de los desórdenes que pudiera ocasionar. El propio Consejo de Castilla sentenció en una ocasión: "se le tiene por inquieto". ${ }^{96}$ Es por ello que, cuando en 1665, enviaba una relación de jóvenes "no deseados", ${ }^{97}$ lo incluía, aún a sabiendas de que se encontraba todavía en la Nueva España, con la orden tajante, de que convenía que

"se vayan a el lugar que eligieren de los estados de sus padres o de los suyos, a veinte leguas de la Corte en el lugar que escogieren, que aunque este castigo es ligero, como se executa en personas de tan grandes prerrogativas producirá escarmiento...".

No se posee confirmación del sitio que eligieron sus padres o él, quizás las tierras de sus mayores, ${ }^{98} \mathrm{o}$ si consiguió quedar fuera de esa lista, ocupando más tarde cargos destacados.

Nuestra virreina murió en Madrid, a la edad de 58 años, el 7 de enero de 1676. En esa misma fecha, el conde viudo de Baños entró de carmelita descalzo en el monasterio de San Pedro Extramuros de Pastrana, donde el 10 de octubre de 1677 tomó el hábito y profesó con el nombre de fray Juan de San José, cantando la primera misa el 27 siguiente. Ya había fallecido al comenzar el año $1678 .{ }^{99}$

$$
* * *
$$

94 Buen amigo de la familia; recordemos que en el Corpus de 1664, la virreina asistió a su casa, para ver pasar la procesión. Ver nota 45 e Ibidem, p. 559.

95 Documentos, 1853-1854, T. II, p. 17 y Robles, 1972, T. I, p. 18.

96 Sáenz Berceo, 1997, p. 102.

97 Entre estos jóvenes se citaban también a don Antonio de Toledo, primogénito del duque de Alba; el conde de Miranda; el conde de Alcautín, hijo mayor del conde de Medellín; el marqués del Valle, hijo mayor del duque de Terranova (descendientes de Hernán Cortés), el conde de Cifuentes, don Fernando de Toledo, hermano y legítimo. Idem.

98 Ibidem, pp. 102 y 103.

99 Fernández de Béthencourt, 2003, T. V, p. 361. 
El problema histórico central de este periodo de gobierno reside en explicar por qué la Nueva España, que mostró tanta sumisión con el gobernante anterior, en cambio con el conde de Baños se reveló tan tensa, irritada y resentida. Según J. I. Israel, parte de la respuesta a esta cuestión se halla en las afirmaciones de sus detractores, los cuales sostienen que este virrey siempre estuvo "cautivo" de su mujer, de su médico ${ }^{100} \mathrm{y}$ de la gente malvada que los rodeaba. Consecuentemente, a los criollos no se les daban nombramientos administrativos, que en cambio se otorgaban invariablemente a parientes, amigos y aduladores de los condes, o, en el caso de que fueran empleos de menor importancia, al mejor postor. ${ }^{101}$

Somos conscientes de que en estas centurias, las figuras femeninas, por muy alta que fuera la categoría profesional del esposo en el Nuevo Mundo, apenas merecían ser reseñadas, apareciendo casi desdibujadas, desconociéndose en ocasiones, cuando acudimos a la bibliografía, si tan siquiera existieron o llegaron a acompañar a sus cónyuges en sus destinos transatlánticos. En este caso, tuvimos la suerte de constatar que, ese recio carácter y don de mando que caracterizaron a doña Mariana Isabel, ${ }^{102}$ esposa del virrey don Juan de Leiva y de la Cerda, además de la desordenada vida y costumbres de algunos de sus hijos, habían generado información documental, por lo anormal y crítico de la situación, como al inicio planteábamos.

Desde hace ya algún tiempo venimos dedicando nuestra atención a las virreinas, esas destacadas damas de las que intentaremos ir desvelando lo poco o mucho que la documentación y bibliografía nos han legado, para irlas así colocando en el lugar correspondiente de una Historia que, hasta ahora, y en la mayoría de las circunstancias, les había negado, no ya su importancia, sino incluso su presencia.

100 Ver nota 52.

101 Israel, 1996, p. 262.

102 Romero de Terreros, 1944, pp. 27 y 28. Este mismo autor escribió un artículo sobre esta virreina y su antecesora: "Virreinas de la Nueva España. La duquesa de Alburquerque y la condesa de Baños”, El País, 15 de diciembre, 1912, en Maura Ocampo y otros, 2004, http://books. 


\section{Bibliografía}

500 años de México en documentos. Papel en que se refieren los servicios que hizo a su majestad el conde de Baños, Juan de Leyva y de la Cerda. Ca. 1660, en http://www.biblioteca.tv/artman2/publish/1660_401/Papel_en_que_se_refier en_los_servicios_que_hizo_a_1191.shtml (consultado el 5 de febrero de 2009).

Lucas Alamán: Disertaciones sobre la Historia de la República mejicana desde la época de la conquista que los españoles hicieron a fines del siglo XV y principios del XVI de las islas y continente americano hasta la independencia, 3 vols., México, Editorial Jus, 1849.

Isabel Arenas Frutos: "Fundación y primeros tiempos del convento de Jesús María de México (1580-1600)", en Actas del I Congreso Internacional de la Orden Concepcionista, 2 vols., León, Universidad de León, 1990, t. I, pp. 475-484.

Alberto Baena Zapatero: "Las virreinas novohispanas y sus cortejos. Vida cortesana y poder indirecto (siglos XVI-XVII)", José Martínez Millán, M. ${ }^{a}$ Paula Marçal Lourenço (coords.), Las relaciones discretas entre las monarquías hispana y portuguesa. Las Casas de las Reinas (siglos XV-XIX). 3 vols. Madrid. Ediciones Polifemo, 2008, t. II, pp. 819-837.

José Bravo Ugarte, SJ: Diócesis y obispos de la Iglesia mexicana, 1519-1939, México, Editorial Buena Prensa, 1940.

Andrés Cavo: Historia de México, México, Editorial Patria, SA, 1949.

- Los tres siglos de Méjico durante el gobierno español hasta la entrada del ejército trigarante, México, Imprenta de Juan R. Navarro, Editor, 1852.

Gustavo Curiel: "Fiestas para un virrey. La entrada triunfal a la ciudad de México del conde de Baños. El caso de un patrocinio oficial", Gustavo Curiel (comp.), Patrocinio, colección y circulación de las artes. XX Coloquio Internacional de Historia del Arte, México, Instituto de Investigaciones Estéticas, Universidad Nacional Autónoma de México (UNAM), 1997, pp. 155-193.

Documentos para la Historia de México, 7 tomos (5 vols), México, Imprenta de Juan R. Navarro, 1853-1854.

Iván Escamilla González: "La corte de los virreyes", Pilar Gonzalbo Aizpuru (dir.), Historia de la vida cotidiana en México, 5 vols., Antonio Rubial García (coord.), t. II: La ciudad barroca, México, FCE, 2005, pp. 371-406.

Manuel Fernández Álvarez: Casadas, Monjas, Rameras y Brujas. La Olvidada Historia de la Mujer Española en el Renacimiento, Madrid, Editorial Espasa Calpe, SA, 2002.

Francisco Fernández de Béthencourt: Historia genealógica y heráldica de la monarquía española, casa real y grandes de España, 10 vols., Sevilla, Fabiola de Publicaciones Hispalenses, 2003. 
¿SÓLO UNA VIRREINA CONSORTE DE LA NUEVA ESPAÑA? 1660-1664

Lewis Hanke, con la colaboración de Celso Rodríguez: Los virreyes españoles en América durante el gobierno de la Casa de Austria. México, 5 vols., Madrid, Editorial Atlas, 1978-1980.

- http://www2.uah.es/cisneros/carpeta/galpersons.php?pag=personajes\&id= 244 (consultado el 22 de diciembre de 2008).

— http://es.wikipedia.org/wiki/Museo_de_la_Ciudad_de_M\%C3\%A9xico (consultado el 20 de febrero de 2009).

- http://www.corazones.org/maria/america/bolivia_virgen.htm (consultado el 21 de febrero de 2009).

- http://www.geneall.net/H/access.php (consultado el 20 de diciembre de 2008).

- http://www.juridicas.unam.mx/publica/librev/rev/hisder/cont/3/est/est10.pdf (consultado el 12 de mayo de 2009).

Jonathan I. Israel: Razas, clases sociales y vida política en el México colonial (1610-1670), México DF, FCE, (Primera reimpresión), 1996.

Doris M. Ladd: La nobleza mexicana en la época de la Independencia, 1780-1826, México DF, FCE, 1984.

Pilar Latasa Vassallo: "La casa del obispo-virrey Palafox: familia y patronazgo. Un análisis comparativo con la corte virreinal hispanoamericana", Congreso Internacional IV Centenario del nacimiento de Don Juan Palafox y Mendoza, Pamplona, Universidad de Navarra, 2001, pp. 201-228.

- "La corte virreinal novohispana: El virrey y su casa, imágenes distantes del rey y su corte (S. XVII)", Eugénio dos Santos (ed), Actas do XII Congresso Internacional de AHILA, Oporto, Centro Leonardo Coimbra da Faculdade de Letras da Universidade do Porto, 2002, pp. 115-130.

Gregorio Martín de Guijo: Diario, 1648-1664, 2 vols. México, Editorial Porrúa, SA, 1953.

Francisco de la Maza: La ciudad de México en el siglo XVII, México, FCE, 1968. Aurora Maura Ocampo y Otros: Diccionario de escritores mexicanos, México, UNAM, 2004. En concreto, para este escritor, pp. 363-369, p. 365, en http://books.google.es/books?id=n_UmYQM6NgEC\&pg=PA365\&dq= virreinas\&lr=\#PPA368,M1 (consultado el 6 de mayo de 2009).

José de J. Núñez y Domínguez: La virreina mexicana Doña María Francisca de la Gándara de Calleja, México, Imprenta Universitaria, 1950.

Manuel A. de Paz Sánchez y Manuel V. Hernández González: La América Española (1763-1898). Cultura y vida cotidiana, Madrid, Editorial Síntesis, 2000.

Nelly R Porro Girardi: "La relación criado/señor en el ámbito privado de las cortes virreinales. Siglos XVI-XVII", en Eugenio dos Santos (ed.), Actas do XII Congresso Internacional de AHILA, pp. 227-240.

Pierre Ragon: "Servir a la Corona: Los pasos en falso del conde de Baños, virrey de la Nueva España (1600-1664)", Anuario de Estudios Americanos, vol. 67, n. ${ }^{\circ} 1$, Sevilla, enero-junio de 2010, pp. 157-187. 
Carmen Ramos Escandón et al.: Presencia y transparencia: la mujer en la historia de México, México DF, El Colegio de México, 1987.

Manuel Ramos Medina: Imagen de santidad en un mundo profano, México DF, Universidad Iberoamericana, 1990.

Vicente Riva Palacio: Resumen integral de México a través de los siglos, 5 vols., 9. a edición, México, Compañía General de Ediciones SA, 1968, t. II: El virreinato.

Antonio de Robles: Diario de sucesos notables (1665-1703), 3 vols., México, Editorial Porrúa, 1972.

Inmaculada Rodríguez Moya: La mirada del virrey. Iconografía del poder en la Nueva España, Castellón de la Plana, Universitat Jaume I, 2005.

Manuel Romero de Terreros: Bocetos de la vida social en la Nueva España, México DF, Editorial Porrúa, SA, 1944.

- "Virreinas de la Nueva España. La duquesa de Alburquerque y la condesa de Baños", El País, 15 de diciembre de 1912, en Aurora Maura Ocampo et al: Diccionario de escritores mexicanos, México, UNAM, 2004. En concreto, para este escritor, pp. 363-369, p. 365, en, http://books.google.es/books?id= n_UYQM6NgEC\&pg=PA365\&dq=virreinas\&lr=\#PPA368,M1 (consultado el 6 de mayo de 2009).

Antonio Rubial García: Monjas, cortesanos y plebeyos. La vida cotidiana en la época de Sor Juana, México DF, Taurus Historia, 2005.

Jorge Ignacio Rubio Mañé: Introducción al estudio de los virreyes de Nueva España (1535-1746), México DF, Universidad Nacional Autónoma de México-Instituto de Historia, Ediciones Selectas,1955, 4 vols..

María del Carmen Sáenz Berceo: El régimen señorial en Castilla: El Estado de Baños y Leiva, Logroño, Universidad de la Rioja, 1997.

Carmelo Sáenz de Santa María: "Los viajes de Gage en el siglo XVII hispanoamericano", IV Congreso de la Asociación Hispanista, Salamanca, 1971, en http://cvc.cervantes.es/obref/aih/pdf/04/aih_04_2_052.pdf (consultado el 26 de febrero de 2008).

M. a Justina Sarabia Viejo: "Velasco y Castilla, Luis de", en Diccionario Biográfico Español, Real Academia de la Historia, http://www.rah.es/diccBio grafico.htm (consultado el 12 de mayo de 2009).

Ernst Schäfer: El Consejo Real y Supremo de las Indias. Su historia, organización y labor administrativa hasta la terminación de la Casa de Austria, 2 vols., Sevilla, Escuela de Estudios Hispano-Americanos (CSIC), 1947.

Sara Sefchovich: La suerte de la consorte. Las esposas de los gobernantes de México: historia de un olvido y relato de un fracaso, México DF, Editorial Océano, 11. ${ }^{\text {a }}$ reimpresión, 1999.

Nelly Sigaut: José Juárez. Recursos y discursos del arte de pintar, México DF, Consejo Nacional para la Cultura y las Artes-Museo Nacional de Arte AC, 2002, http://books.google.es/books?id=oTqphaugaU4C\&dq=Jos\%C3\%A9+ 
$\mathrm{Ju} \% \mathrm{C} 3 \% \mathrm{~A} 1$ rez.+Recursos+y+discursos+del+arte+de+pintar\&printsec=fron tcover \& source $=$ bl\&ots $=$ LNqGaamlx $3 \&$ sig $=$ tay KwBCtXpLrGRg LP_rrZ8nXY\&hl=es\&ei=eT-hSfObFOTSjAe 1 tnQCw\&sa=X\&oi= book_result\&resnum=1\&ct=result\#PPA272,M1 (consultado el 3 de febrero de 2009).

Reiko Tateiwa: “¿El peor virrey de la Nueva España es el héroe de las Filipinas?: Revisión del gobierno virreinal del conde de Baños", en http://syutin.cside. ne.jp/fiealc/sum09.html (consultado el 4 de marzo de 2009).

Ernesto de la Torre Villar: Advertencias acerca del sistema virreinal novohispano, p. 289, en http://www.juridicas.unam.mx/publica/librev/rev/hisder/cont/3/ est/est10.pdf (consultado el 12 de mayo de 2009).

Eduardo Torres Arancivia: Corte de virreyes. El entorno del poder en el Perú del siglo XVII, Lima, Pontificia Universidad Católica del Perú, Fondo Editorial, 2006.

Artemio de Valle-Arizpe: Virreyes y Virreinas de la Nueva España. Tradiciones, leyendas y sucedidos del México virreinal, México DF, Editorial Porrúa, 2000.

Fray Agustín de Vetancurt: Teatro mexicano. Descripción breve de los sucessos ejemplares de la Nueva España en el Nuevo Mundo occidental de las Indias, 4 vols., Madrid, Imprenta José Porrúa Turanzas, 1960, T. II. 